\title{
ENRAIZAMENTO DE DIFERENTES TIPOS DE ESTACAS DE ACEROLEIRA UTILIZANDO ÁCIDO INDOLBUTÍRICO ${ }^{1}$
}

\author{
TIAGO CHALTEIN ALMEIDA GONTIJO², JOSÉ DARLAN RAMOS 3 , VANDER MENDONÇA ${ }^{4}$, RAFAEL PIO 5 , \\ SEBASTIÃO ELVIRO DE ARAÚJO NETO ${ }^{6}$, FERNANDO LUIZ DE OLIVEIRA CORRÊA ${ }^{7}$
}

\begin{abstract}
RESUMO - Este trabalho teve como objetivo avaliar a influência do número de pares de folhas e testar o efeito de diferentes concentrações de AIB (ácido indolbutírico) no enraizamento de estacas semilenhosas de aceroleira. O delineamento experimental utilizado foi o inteiramente casualizado, em fatorial 5 x 3, com cinco concentrações diferentes de AIB $\left(0 ; 1600 ; 2000 ; 2400\right.$ e 2800 mg.L $\mathrm{L}^{-1}$ ) e três tipos de estacas (sem folhas, com um par de folhas e com dois pares de folhas). As estacas foram obtidas de plantas da coleção de matrizes do pomar da UFLA, sendo padronizadas com $15 \mathrm{~cm}$ de comprimento. Após o preparo das estacas, estas foram imersas nas soluções de AIB por 5 segundos, em seguida colocadas em bandejas de polipropileno contendo o substrato vermiculita e transportadas para casa de vegetação com umidade e temperatura controladas, onde permaneceram por 100 dias. As variáveis analisadas foram: porcentagem de enraizamento, comprimento da raiz, $\mathrm{n}^{\circ}$ de raízes e massa seca das raízes. A presença de folhas é importante para o enraizamento de estacas de aceroleira; em estacas sem folhas, não ocorreu a formação de raízes. Estacas de aceroleira com dois pares de folhas tratadas com $2800 \mathrm{mg} . \mathrm{L}^{-1}$ de AIB apresentaram maiores porcentagens de enraizamento (50\%) e comprimento das raízes ( $\left.9 \mathrm{~cm}\right)$. A concentração de $2800 \mathrm{mg} . \mathrm{L}^{-1}$ de AIB proporcionou maior número e massa seca das raízes por estaca de aceroleira. A presença de dois pares de folhas em estacas de aceroleira proporcionou maior número e massa seca das raízes.
\end{abstract}

Termos para indexação: Malpighia glabra L.; propagação; AIB.

\section{ROOTING OF DIFFERENT TYPES OF ACEROLA CUTTINGS USING INDOL BUTIRIC ACID}

\begin{abstract}
The objective of this work was to evaluate the influence of the number of leaves and test the effect of different doses of IBA (indolbutiric acid) in cutting propagation of acerola. The experimental design was entirely randomized, in a factor arrangement (5 X 3 ), with five different concentration of IBA $\left(0,1600,2000,2400\right.$ and $\left.2800 \mathrm{mg} \cdot \mathrm{L}^{-1}\right)$ and three different types of cuttings (without leaves, one pair of leaves and two pairs of leaves). The cuttings were obtained from plants of the UFLA's orchard collection, padronized with $15 \mathrm{~cm}$ of length and treated with solution of IBA for 5 seconds. After that, they were taken to polypropylene trays filled with vermiculite and stayed under greenhouse conditions for 100 days. Rooting percentage, roots length, number of leaves and roots dry matter were evaluated. The presence of leaves is important for the rooting of aceroleira cuttings, in cuttings without leaves it didn't occur the formation of roots. Aceroleira cuttings with two pairs of leaves, treated with 2800 $\mathrm{mg} . \mathrm{L}^{-1}$ of IBA presented larger rooting percentage $(50 \%)$ and length of the roots $(9 \mathrm{~cm})$. The concentration of $2800 \mathrm{mg} . \mathrm{L}^{-1}$ of IBA provided larger number and dry matter of the roots for aceroleira rooting. The two pairs of leaves in aceroleira rooting provided larger number and dry matter of the roots.
\end{abstract}

Index terms: Malpighia glabra L.; propagation; IBA.

\section{INTRODUÇÃO}

O cultivo da aceroleira teve um grande impulso nos últimos anos, devido à elevada taxa de ácido ascórbico (vitamina C) presente nos frutos (Junqueira et al., 2002). Apesar de toda a perspectiva real e potencial que envolve o cultivo da aceroleira no Brasil, a realidade é diferente, pois, na maioria das áreas já estabelecidas, utilizam-se mudas provenientes de sementes, o que propicia a desuniformidade dos pomares (Neto et al., 1996), pois a propagação da aceroleira por via sexual apresenta como inconveniente a segregação hereditária (Martins et al., 2000).

O domínio do método de propagação é fundamental, tanto para o melhorista, como para o agricultor e a indústria, por assegurar a formação de plantios uniformes de aceroleira e de qualidade (Gomes et al. 2000). A propagação por estaquia, que é um dos métodos mais importantes no processo de propagação vegetativa, destaca-se por promover a multiplicação de plantas-matrizes selecionadas, mantendo as características desejáveis da mesma (Meletti, 2000). No entanto, existem espécies que apresentam facilidade em emitir raízes adventícias de suas estacas, outras as emitem regularmente e aquelas com dificuldade no enraizamento (Tofanelli, 1999). A propagação comercial de mudas por estaquia é viável, mas dependente da capacidade de enraizamento de cada espécie, da qualidade do sistema radicular formado e do desenvolvimento posterior da planta (Fachinello et al., 1995). Tem-se observado que a dificuldade no enraizamento de estacas de algumas espécies pode ser superada se forem fornecidas condições e fatores ótimos para o enraizamento das mesmas (Oliveira, 2000).

A dificuldade de enraizamento das estacas, envolvendo a participação tanto de fatores relacionados à própria planta como também ao ambiente, constitui um dos mais sérios problemas, sendo importante a busca de técnicas auxiliares, como o uso de reguladores de crescimento, para assim proporcionar uma melhoria do enraizamento (Biasi, 1996; Mayer, 2001). O grupo de reguladores de crescimento usado com maior freqüência é o das auxinas, que são essenciais no processo de enraizamento, possivelmente por estimularem a síntese de etileno, favorecendo assim a emissão de raízes (Norberto et al., 2001). Segundo Pasqual et al. (2001), é necessário que haja um balanço hormonal endógeno adequado, especialmente entre auxinas, giberelinas e citocininas, ou seja, equilíbrio entre promotores e inibidores do processo de iniciação radicular. A maneira mais comum de promover esse equilíbrio é pela aplicação exógena de reguladores de crescimento sintéticos, como AIB (ácido indolbutírico), que podem elevar o teor de auxina no tecido.

A presença de folhas no enraizamento de estacas influencia no processo de formação radicular, auxiliando no transporte de substânci-

\footnotetext{
${ }^{1}$ (Trabalho 106/2002). Recebido: 18/07/2002. Aceito para publicação: 30/07/2003.

${ }^{2}$ Graduando do curso de Agronomia, Bolsista de Iniciação Científica-CNPq, Universidade Federal de Lavras/UFLA. Tel. (35)3822-5631. tiagocgontijo@ hotmail.com. ${ }^{3}$ Eng. Agrônomo, Dr., Prof. Adjunto IV do Depto. de Agricultura, Universidade Federal de Lavras/UFLA, C.P. 37, CEP 37200-000, Lavras-MG. Tel. (35)3829-1339. darlan@ufla.br.

${ }^{4}$ Eng. Agrônomo, M.Sc., Doutorando do curso de Fitotecnia, Universidade Federal de Lavras/UFLA. Tel. (35)3822-5210. vander@ufla.br.

${ }^{5}$ Eng $^{\circ}$. Agrônomo, M.Sc., Doutorando do curso de Fitotecnia, Universidade de São Paulo, Escola Superior de Agricultura “Luiz de Queiroz" - ESALQ/USP. Rua Nove, n.168 - Iate Clube de Americana, CEP 13465-000, Americana-SP. Autor para correspondência. Tel. (19)3465-1493. rafapio@esalq.usp.br.

${ }^{6}$ Eng. Agrônomo, M.Sc., Doutorando do curso de Fitotecnia, Universidade Federal de Lavras/UFLA. Tel. (35)3822-3368. selviro@ zipmail.com.br.

${ }^{7}$ Eng. Agrônomo, M.Sc., Doutorando do curso de Fitotecnia, Universidade Federal de Lavras/UFLA. Tel. (35)3821-1229. fernando@ ufla.br.
} 
as promotoras de enraizamento e promovendo a perda de água por transpiração (Costa Júnior, 2000). Musser et al. (1987), citados por Bueno (1995), concluem que a utilização de auxinas, associada à presença de folhas, favorece o aumento da porcentagem de estacas enraizadas de aceroleira.

Sendo assim, este trabalho teve como objetivo avaliar a influência do número de pares de folhas e testar o efeito de diferentes concentrações de AIB (ácido indolbutírico) no enraizamento de estacas semilenhosas de aceroleira.

\section{MATERIAL E MÉTODOS}

O presente trabalho foi desenvolvido no período de dezembro a março de 2001, nas dependências do pomar do Departamento de Agricultura da Universidade Federal de Lavras - UFLA, situado no município de Lavras-MG.

As estacas foram coletadas da porção mediana de ramos de plantas-matrizes, sendo padronizadas com $15 \mathrm{~cm}$ de comprimento. $\mathrm{O}$ delineamento experimental utilizado foi o inteiramente casualizado, em esquema fatorial 5 x 3 , com cinco concentrações diferentes de AIB $(0$; 1600; 2000; 2400 e 2800 mg.. - $^{-1}$ ) e três tipos de estacas (sem folhas, com um par de folhas e com dois pares de folhas), com 4 repetições e 10 estacas por parcela. As estacas foram imersas nas soluções de AIB por 5 segundos, para então serem colocadas em bandejas de polipropileno contendo o substrato vermiculita, sendo transportadas para casa de vegetação com umidade e temperatura controladas.

As avaliações foram realizadas 100 dias após a instalação do ensaio, através de coleta dos seguintes dados biométricos: porcentagem de enraizamento, comprimento da raiz, $\mathrm{n}^{\circ}$ de raízes e massa seca das raízes. Os dados experimentais foram submetidos à análise de variância, as médias ao teste Tukey e os níveis de AIB à regressão, ao nível de 0,05 de probabilidade, sendo seguidas as recomendações de Gomes (2000). As análises foram realizadas pelo programa computacional Sistema para Análise de Variância - SISVAR (Ferreira, 2000).

\section{RESULTADOS E DISCUSSÕES}

Houve efeito significativo da interação entre as concentrações de AIB e o tipo de estaca (número de pares de folhas na estaca) na porcentagem de enraizamento e no comprimento da raiz. As maiores porcentagens de enraizamento (50\%) foram obtidas em estacas de aceroleira com dois pares de folhas e tratadas com 2800 mg. $\mathrm{L}^{-1}$ de AIB (Figura 1).

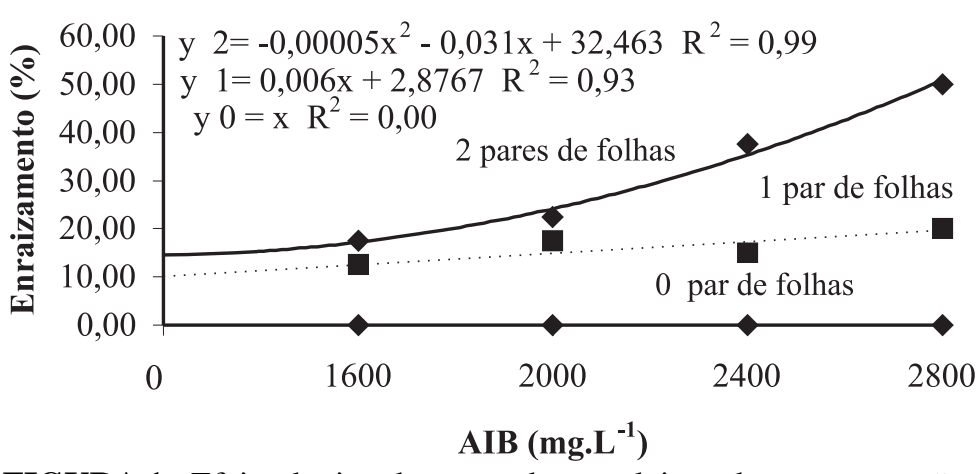

FIGURA 1 - Efeito do tipo de estaca de aceroleira e das concentrações de AIB no enraizamento. Lavras-MG, UFLA, 2002.

Os resultados apresentados na Figura 1 discordam dos obtidos por Meletti (2000), que obteve taxas significativas de enraizamento de estacas de aceroleira com a concentração de $2000 \mathrm{mg} . \mathrm{L}^{-1}$ de AIB. Musser et al. (1987), trabalhando com estacas semilenhosas de acerola em sistema de microaspersão e tratadas com 2000 mg.L. - $^{-1}$ ANA, obtiveram 51,7\% de enraizamento. Duarte et al. (2000) obtiveram melhores resultados no enraizamento de estacas semilenhosas de aceroleira com a dosagem de 2000 mg.L.-1 de AIB. De acordo com Nascimento (1991), a faixa de concentração entre 2000 e $8000 \mathrm{mg} . \mathrm{L}^{-1}$ tem efeito prejudicial no enraizamento de estacas semilenhosas de aceroleira.

Observa-se na Figura 1 que estacas sem folhas não apresentaram quaisquer sinais de enraizamento, levando à não-sobrevivência das mesmas.

Com relação ao comprimento de raiz (Figura 2), observa-se que as raízes cresceram mais com o aumento da concentração de AIB em estacas com um e dois pares de folhas. O maior comprimento da raiz ( 9 $\mathrm{cm}$ ) foi obtido na concentração de $2800 \mathrm{mg} . \mathrm{L}^{-1}$ de AIB em estacas com dois pares de folhas.

Para as variáveis número de raízes e massa seca das raízes, verificaram-se diferenças significativas entre as concentrações de AIB e entre os tipos de estacas. Nas Figuras 3 e 4, observa-se que, com o aumento das concentrações de AIB, houve um aumento no número e na massa seca das raízes das estacas de aceroleira. A concentração de 2800 $\mathrm{mg} . \mathrm{L}^{-1}$ de AIB proporcionou maior número de raízes por estaca $(2,5)$ e maior massa seca das raízes $(6,7 \mathrm{mg})$. $\mathrm{O}$ tratamento com auxinas, em especial o AIB, na base das estacas, propicia efeitos benéficos no tocante ao peso e qualidade do sistema radicular formado, segundo Pasqual et al. (2001).

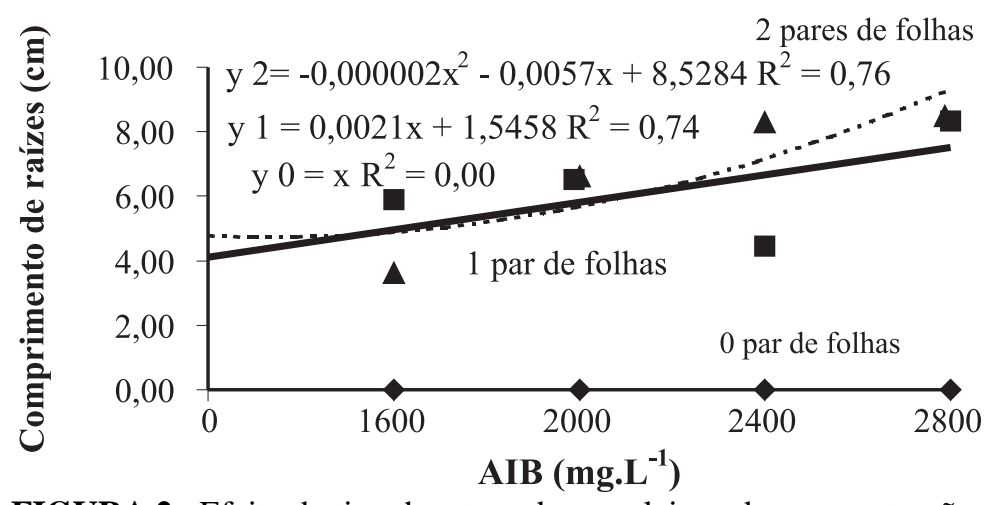

FIGURA 2 - Efeito do tipo de estaca de aceroleira e das concentrações de AIB no comprimento de raízes. Lavras-MG, UFLA, 2002.

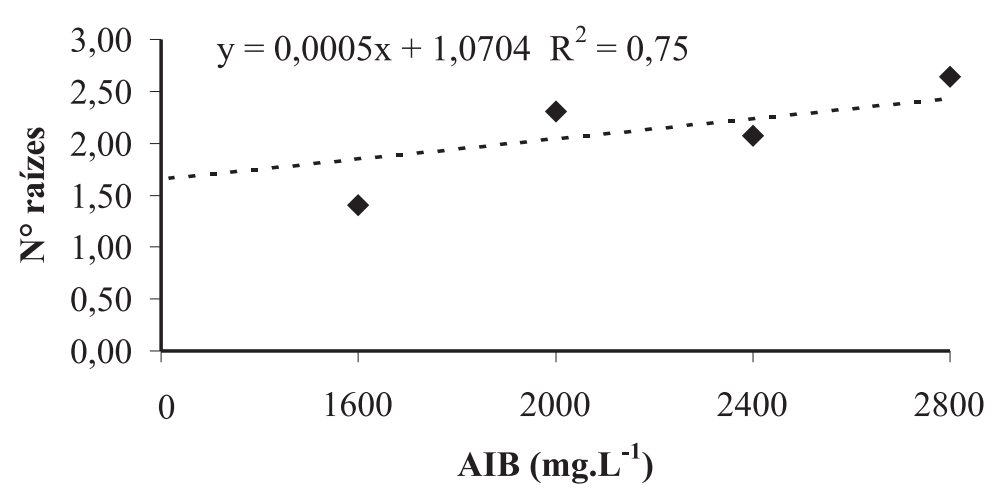

FIGURA 3 - Efeito das concentrações de AIB no número de raízes de estacas de aceroleira. Lavras-MG, UFLA, 2002.

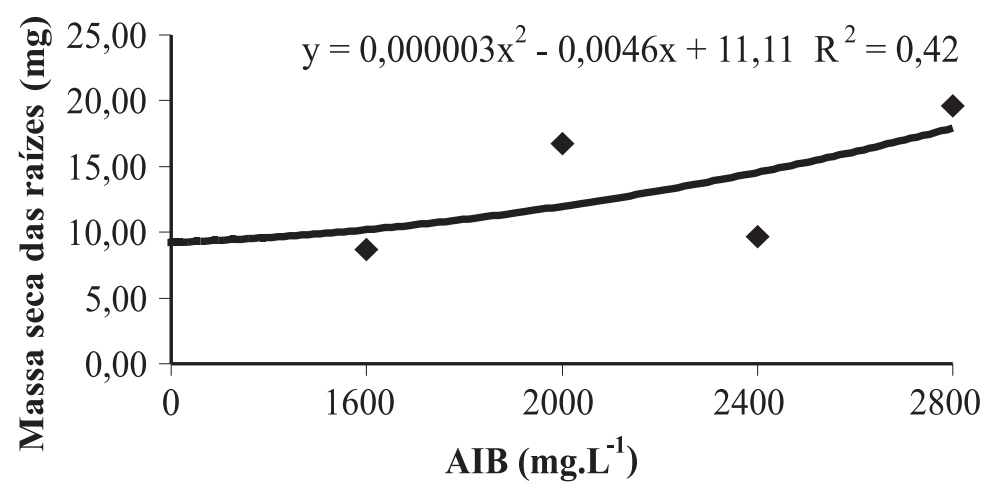

FIGURA 4 - Efeito das concentrações de AIB na massa seca das raízes de estacas de aceroleira. Lavras-MG, UFLA, 2002. 
Na Tabela 1, verifica-se que a presença de dois pares de folhas em estacas de aceroleira proporcionou maior número $(3,73)$ e massa seca $(28,85 \mathrm{mg})$ de raízes por estaca. As folhas são requisitos essenciais para o enraizamento das estacas (Silva, 1998), tendo demonstrado grande participação no processo de enraizamento, por contribuírem com substâncias benéficas ao mesmo (Oliveira, 2000). Trabalho desenvolvido por Biasi et al. (1997) constatou fundamental importância da presença de folhas para o enraizamento das estacas semilenhosas de porta-enxertos de videira, não ocorrendo formação de raízes em estacas ausentes de folhas. De acordo com Araújo e Minami (1994), o enraizamento de estacas de aceroleira com folhas, em ambiente sob nebulização intermitente, proporcionou bons resultados.

TABELA 1 - Valores médios do número de raízes e da massa seca das raízes de estacas de aceroleira com um e dois pares de folhas e sem folhas. Lavras-MG, UFLA, 2002.

\begin{tabular}{|c|c|c|}
\hline \multicolumn{3}{|c|}{ Variáveis Analisadas* } \\
\hline Tipo de estaca & $\begin{array}{c}\mathrm{n}^{\circ} \mathrm{de} \\
\text { raízes/estaca }\end{array}$ & $\begin{array}{l}\text { massa seca das } \\
\text { raízes (mg) }\end{array}$ \\
\hline Estacas com dois pares de folhas & 3,73 a & 28,85 a \\
\hline Estacas com um par de folhas & 2,05 & $10,60 \mathrm{~b}$ \\
\hline Estacas sem folhas & 0 & 0 \\
\hline & cv: $22,36 \%$ & cv: $21,60 \%$ \\
\hline
\end{tabular}

* Médias seguidas da mesma letra na coluna não diferem significamente entre si, pelo teste de Tukey a 0,05 .

\section{CONCLUSÕES}

Nas condições em que o presente trabalho foi conduzido, permitem-se as seguintes conclusões:

1) A presença de folhas é importante para o enraizamento de estacas de aceroleira; em estacas sem folhas não ocorreu a formação de raízes.

2) Estacas de aceroleira com dois pares de folhas tratadas com $2800 \mathrm{mg} . \mathrm{L}^{-1}$ de AIB apresentaram maiores porcentagens de enraizamento $(50 \%)$ e comprimento de raízes $(9 \mathrm{~cm})$.

3) A concentração de $2800 \mathrm{mg} . \mathrm{L}^{-1}$ de AIB proporcionou maior número e massa seca das raízes por estaca de aceroleira.

4) A presença de dois pares de folhas em estacas de aceroleira proporcionou maior número e massa seca das raízes.

\section{REFERÊNCIAS BIBLIOGRÁFICAS}

ARAÚJO, P.S.R.; MINAMI, K. Acerola. Campinas: Fundação Cargill, 1994. 81p.

BIASI, L.A. Emprego do estiolamento na propagação de plantas. Ciência Rural, Santa Maria, v.26, n.2, p.309-315, 1996.

BIASI, L.A.; POMMER, C.V.; PINO, P.A.G.S. Propagação de porta-enxertos de videira mediante estaquia semilenhosa. Bragantia, Campinas, v.56, n.2, p.367-376, 1997.

BUENO, S.C.S. Estudos de diversos tipos de propagação da aceroleira (Malpighia glabra L.), 1995. 76f. Dissertação (Mestrado em Agronomia) Escola Superior “Luiz de Queiroz", Universidade de São Paulo, Piracicaba, 1995

COSTA JÚNIOR, W.H. da. Enraizamento de estacas de goiabeira: influência de fatores fisiológicos e mesológicos. 2000. 66f. Dissertação (Mestrado em Agronomia) Escola Superior “Luiz de Queiroz”, Universidade de São Paulo, Piracicaba, 2000.

DUARTE, O.R.; MOREIRA, M.A.B.; BENEZAR, R.M.C.; COSTA, M.I. da S.; FREITAS, F.N. de. Efeito do ácido indolbutírico (AIB) em duas épocas, no enraizamento de estacas semilenhosas de acerola
(Malpighia glabra L.). In: CONGRESSO BRASILEIRO DE FRUTICULTURA, 16., 2000, Fortaleza. Anais... Fortaleza: SBF, 2000. CDROM.

FACHINELLO, J.C.; HOFFMANN, A.; NACHTIGAL, J.C.; KERSTEN, E.; FONTES, G. de R. L. Propagação de plantas frutíferas de clima temperado. Pelotas: UFPel, 1995. 178p.

FERREIRA, D. F. Análise estatística por meio do SISVAR (Sistema para Análise de Variância) para Windows versão 4.0. In: REUNIÃO ANUAL DA REGIÃO BRASILEIRA DA SOCIEDADE INTERNACIONAL DE BIOMETRIA, 45., 2000, São Carlos. Anais... São Carlos: UFSCar, 2000. p. 255-258.

GOMES, F.P. Curso de estatística experimental. 14. ed. Piracicaba: ESALQ/USP, 2000.477p.

GOMES, J.E.; PERECIN, D.; MARTINS, A.B.G.; IGNÁCIO, N. Enraizamento de estacas herbáceas de genótipos de acerola em câmara de nebulização intermitente tratadas com ácido indolbutírico em duas épocas. Revista Brasileira de Fruticultura, Jaboticabal, v.22, n.3, p.407-412, 2000.

JUNQUEIRA, K.P.; PIO, R.; VALE, M.R. do; RAMOS, J.D. Cultura da aceroleira. Lavras: Universidade Federal de Lavras, 2002. 31p. (Boletim técnico, 96).

MARTINS, A.B.G.; NOGUEIRA, J.A.D.; MATTOS, L.P.B. Fatores que afetam a propagação da aceroleira (Malpighia glabra L.) por estaquia herbácea. In: CONGRESSO BRASILEIRO DE FRUTICULTURA, 16., 2000, Fortaleza. Anais... Fortaleza: SBF, 2000. CD-ROM.

MAYER, N.A. Propagação assexuada do porta-enxerto umezeiro (Prunus mume Sieb \& Zucc.) por estacas herbáceas, 2001. 109f. Dissertação (Mestrado em Produção Vegetal) Faculdade de Ciências Agrárias e Veterinárias, Universidade Estadual Paulista, Jaboticabal, 2001.

MELETTI, L.M.M. Propagação de frutíferas tropicais. Guaíba: Agropecuária, 2000. 239p.

MUSSER, R.D.S.; COUCEIRO, E.M.; ALBUQUERQUE, M.H. de. Efeitos do ácido naftalenoacético no enraizamento de estacas semilenhosas de acerola em sistema de microaspersão. In: CONGRESSO BRASILEIRO DE FRUTICULTURA, 9., 1987, Campinas. Anais... Campinas: SBF, 1987. p.79-83.

NASCIMENTO, C.E. de S. Efeito do ácido indolbutírico sobre o enraizamento de estacas semilenhosas de acerola. Revista Brasileira de Fruticultura, Cruz das Almas, v.13, n.3, p.255-257, 1991.

NETO, L.G.; AMARAL, M.G. do; SAUERESSIG, M.E. Enxertia por garfagem e borbulhia em acerola sob telado. Pesquisa Agropecuária Brasileira, Brasília, v.31, n.9, p.635-638, 1996.

NORBERTO, P.M.; CHALFUN, N.N.J.; PASQUAL, M.; VEIGA, R.D.; PEREIRA, G.E.; MOTA, J.H. Efeito da época de estaquia e do AIB no enraizamento de estacas de figueira (Ficus carica L.). Ciência e Agrotecnologia, Lavras, v.25, n.3, p.533-541, maio/jun. 2001.

OLIVEIRA, J.A. Efeito dos substratos artificiais no enraizamento e no desenvolvimento de maracujazeiro-azedo e doce por estaquia, 2000. 71f. Dissertação (Mestrado em Agronomia) Universidade de Brasília, Brasília, 2000

PASQUAL, M.; CHALFUN, N.N.J.; RAMOS, J.D.; VALE, M.R. do; SILVA, C.R.de. R.e Fruticultura Comercial: Propagação de plantas frutíferas. Lavras: UFLA/FAEPE, 2001. 137p.

SILVA, M.N. da. Enraizamento de estacas de seis espécies nativas de mata galeria, 1998. 112f. Dissertação (Mestrado em Ciências Biológicas) Universidade de Brasília, Brasília, 1998.

TOFANELLI, M.B.D. Enraizamento de estacas lenhosas e semilenhosas de cultivares de pessegueiro em diferentes concentrações de ácido indolbutírico. 1999. 87f. Dissertação (Mestrado em Agronomia) Universidade Federal de Lavras, Lavras, 1999. 